\title{
Sublingual atropine for the treatment of severe and hyoscine-resistant clozapine-induced sialorrhea
}

Sialorrhea is a common adverse effect of clozapine therapy ${ }^{1}$ which may increase the risk of aspiration pneumonia², a potentially life threatening condition. M4 agonism, $\alpha 2$ antagonism and impaired deglutition have been hypothesised as probable underlying mechanisms. ${ }^{3} \mathrm{~A}$ few previous case reports have shown topical atropine, an antimuscarinic agent, to be effective in the management of clozapine induced sialorrhea (CIS). ${ }^{4-6}$ Informed consent was received for publication of the following case material.

A 46 year old Afro-Caribbean male with chronic refractory schizophrenia, was compulsorily hospitalised after experiencing an acute psychotic relapse. His relapse was precipitated by clozapine discontinuation. During his hospital treatment, the patient failed to respond to olanzapine up to a dose of $40 \mathrm{mg} /$ day (plasma level $59 \mathrm{mcg} / \mathrm{L}$ ) and was therefore cross tapered to clozapine over a period of 3 weeks. Clozapine was gradually titrated up to $400 \mathrm{mg} /$ day (plasma level $0.26 \mathrm{mg} / \mathrm{L}$ ) and the patient subsequently developed severe sialorrhea. He was constantly drooling and his speech was impaired due to the copious amount of saliva in his mouth. The patient found this adverse effect very distressing. Oral hyoscine hydrobromide was administered for 4 weeks (titrated gradually up to $900 \mathrm{mcg} /$ day) without notable improvement in the patient's hypersalivation. This restricted any further increase in the dose of clozapine, despite the patient's continued psychotic symptoms. Sublingual atropine solution (1\%) was commenced (one drop up to 3 times/day), to which the patient instantaneously responded, and hyoscine hydrobromide was gradually reduced to $300 \mathrm{mcg}$ at bed time. The drooling stopped and the patient's speech normalised. The clozapine dose was increased to $450 \mathrm{mg} /$ day and his mental state started improving steadily. Sialorrhea did not recur following the discontinuation of atropine by the patient after 7 days.

\section{Correspondence}

DrFA Mustafa

email: ferasmustafa@yahoo.com
In this case, sublingual administration of atropine led to dramatic resolution of severe CIS, which had not responded to previous treatment with hyoscine. Atropine treatment provided instantaneous relief from CIS and allowed further increase in the clozapine dose until a therapeutic response was achieved. However, at the end of the 7 day atropine trial, the patient was still receiving hyoscine $300 \mathrm{mcg}$ at bed time. Hence, it could be argued that CIS resolution may have been due to the combined treatment with atropine and hyoscine. CIS did not recur after atropine was discontinued, which suggests that in this patient CIS was a transient adverse effect. This case further supports the use of sublingual atropine in the management of CIS and this should be robustly evaluated using a randomised controlled trial.

\section{FA Mustafa, A Khan, J Burke, M Cox, S Sherif Northamptonshire Healthcare NHS Foundation Trust, Northamptonshire, United Kingdom}

\section{References}

1. Safferman A, Lieberman JA, Kane JM, Szymanski S, Kinon B. Update on the clinical efficacy and side effects of clozapine. Schizophr Bull 1991; 17(2):247-261.

2. Hinkes R, Quesada TV, Currier MB, Gonzalez-Blanco M. Aspiration pneumonia possibly secondary to clozapine-induced sialorrhea.J Clin Psychopharmacol 1996; 16(6):462-463.

3. Praharaj SK, Arora M, Gandotra S. Clozapine-induced sialorrhea: pathophysiology and management strategies. Psychopharmacology (Berl) 2006 ; 185(3):265-273.

4. Antonello C, Tessier P. Clozapine and sialorrhea: a new intervention for this bothersome and potentially dangerous side effect.J Psychiatry Neurosci 1999: 24(3):250.

5. Comley C, Galletly C, Ash D. Use of atropine eye drops for clozapine induced hypersalivation. Aust N Z J Psychiatry 2000 ; 34(6):10331034.

6. Sharma A, Ramaswamy S, Dahl E, Dewan V. Intraoral application of atropine sulphate ophthalmic solution for clozapine-induced sialorrhea. Ann Pharmacother 2004 ; 38(9):1538. 